\title{
Correction of deep overbite and gummy smile by using a mini-implant with a segmented wire in a growing Class II Division 2 patient
}

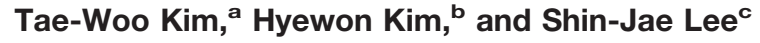 \\ Seoul, South Korea
}

\begin{abstract}
A boy, aged 10.5 years, with a Class II molar relationship and a very deep overbite, complaining of a gummy smile and anterior crowding, was treated nonextraction with a mini-implant and Twin-block and edgewise fixed appliances. Severely extruded and retroclined maxillary incisors were intruded and proclined with a nickel-titanium closed-coil spring anchored to a mini-implant and segmented wires; this resolved the gummy smile and deep overbite efficiently without extruding the maxillary molars or opening the mandible. The mandibular incisors were proclined without direct orthodontic force during intrusion of the maxillary incisors; this helped the nonextraction treatment of mandibular incisor crowding. The Twin-block appliance with high-pull headgear promoted mandibular growth, restrained maxillary growth, and changed the canine and molar relationship from Class II to Class I. The patient's overbite and overjet were overtreated, and, 1 year postretention, the patient maintained a good overbite and overjet. (Am J Orthod Dentofacial Orthop 2006;130:676-85)
\end{abstract}

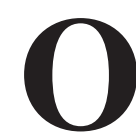
rthodontic mini-implants have revolutionized orthodontic anchorage and biomechanics by making anchorage perfectly stable. Mini-implants have been used to intrude incisors since 1983, when Creekmore and Eklund ${ }^{1}$ reported using a metal implant to correct a deep overbite. They placed a surgical vitallium bone screw just below the anterior nasal spine and used elastic thread to elevate the maxillary central incisors approximately $6 \mathrm{~mm}$ and tip them labially $25^{\circ}$, without infection, pain, or other complications from the screw. But they cautioned that widespread use of the technique would be premature. In 1997, Kanomi ${ }^{2}$ reported that intrusion of mandibular anterior teeth in a patient with a deep overbite was obtained by using a screw $6 \mathrm{~mm}$ long and $1.2 \mathrm{~mm}$ in diameter. Recently, Ohnishi et $\mathrm{al}^{3}$ presented a deep overbite case treated with a mini-implant by intruding the maxillary incisors; this also improved the gummy smile.

This case report presents the treatment of a growing patient with a Class II Division 2 malocclusion whose

From the Department of Orthodontics, School of Dentistry and Dental Research Institute, Seoul National University, Seoul, South Korea.

aprofessor.

${ }^{\mathrm{b}}$ Graduate student.

${ }^{\mathrm{c}}$ Assistant professor

Reprint requests to: Shin-Jae Lee, Department of Orthodontics, School of Dentistry and Dental Research Institute, Seoul National University, 28-22

Yunkeun-Dong, Chongro-Gu, Seoul 110-744, Korea (ROK); e-mail, nonext@ snu.ac.kr.

Submitted, June 2005; revised and accepted, July 2005.

$0889-5406 / \$ 32.00$

Copyright $(9) 2006$ by the American Association of Orthodontists.

doi:10.1016/j.ajodo.2005.07.013 deep overbite and gummy smile were corrected by using a mini-implant with segmented wires.

\section{DIAGNOSIS AND ETIOLOGY}

The patient was a boy, aged 10.5 years, with a Class II molar relationship and a very deep overbite (Fig 1). His chief complaints were a gummy smile and crowding.

The pretreatment facial photographs (Fig 1) show a retrusive mandible and a gummy smile with severe crowding of the maxillary anterior teeth. The maxillary central incisors were long relative to the upper lip. The pretreatment intraoral photographs and the study models (Fig 2) demonstrate a full Class II molar relationship, severe overbite, retroclination of the maxillary central incisors, and moderate (4-5 $\mathrm{mm}$ ) mandibular anterior crowding. In centric occlusion, the mandibular anterior teeth were not seen at all because the mandibular incisors impinged on the palatal tissue.

Cephalometric analysis (Fig 3, $A$ and $B$ ) showed a skeletal Class II relationship (ANB angle, 9.0 $0^{\circ}$ ). A-point was protruded (SNA angle, $83.0^{\circ}$ ), and B-point was retruded (SNB angle, $74.0^{\circ}$ ). The FMA of $28.5^{\circ}$ was in the normal range. Maxillary incisor to FH plane was $86.0^{\circ}$, which is much smaller than normal. IMPA was $79.0^{\circ}$, which is also much smaller than normal. Interincisal angle was $159.5^{\circ}$. In other words, the maxillary and mandibular incisors showed linguoversion, and the mandible was severely retruded. The distance from the incisal edge of the maxillary central incisors to stomion 

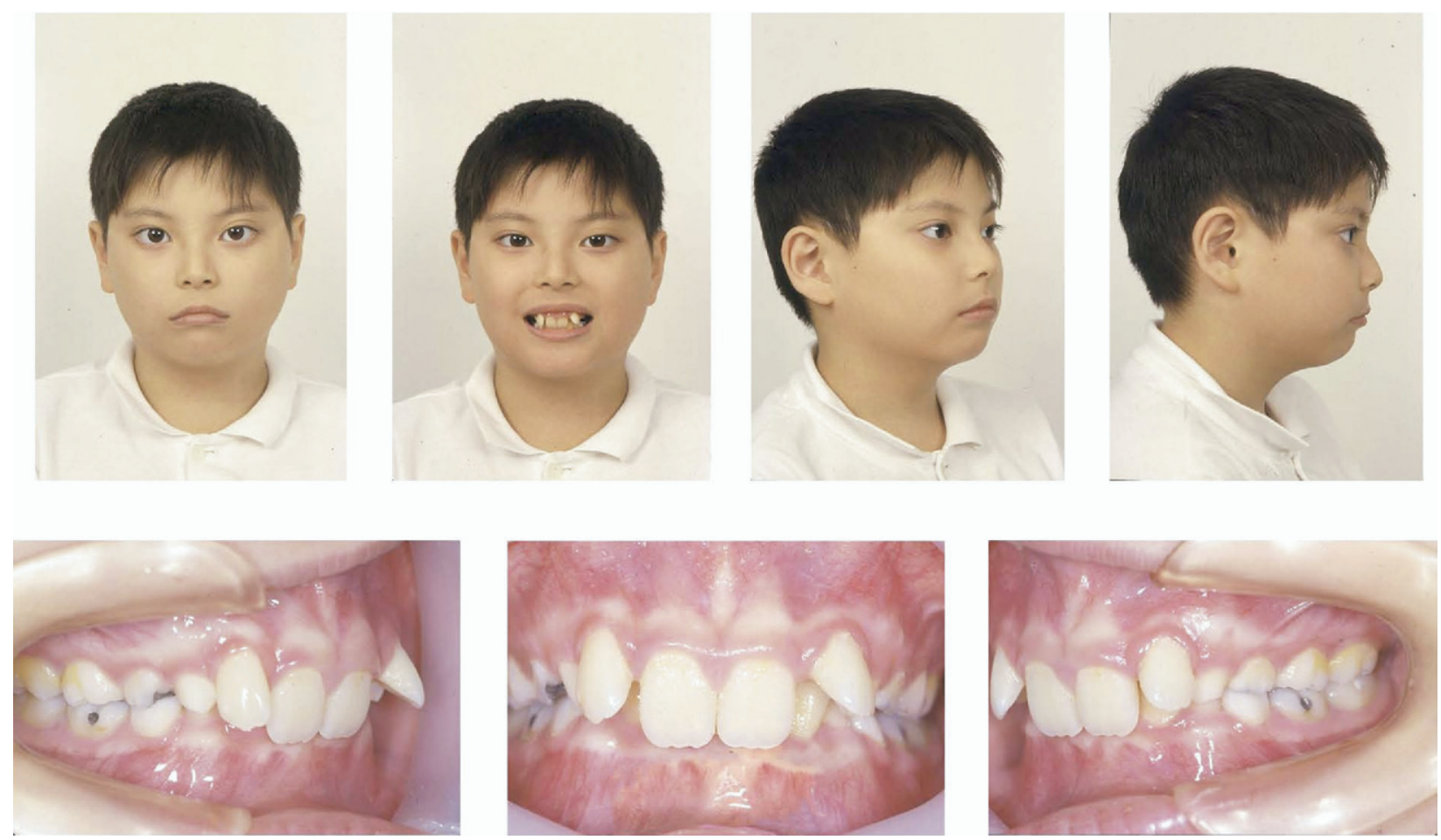

Fig 1. Pretreatment photographs (age, 10 years 6 months).
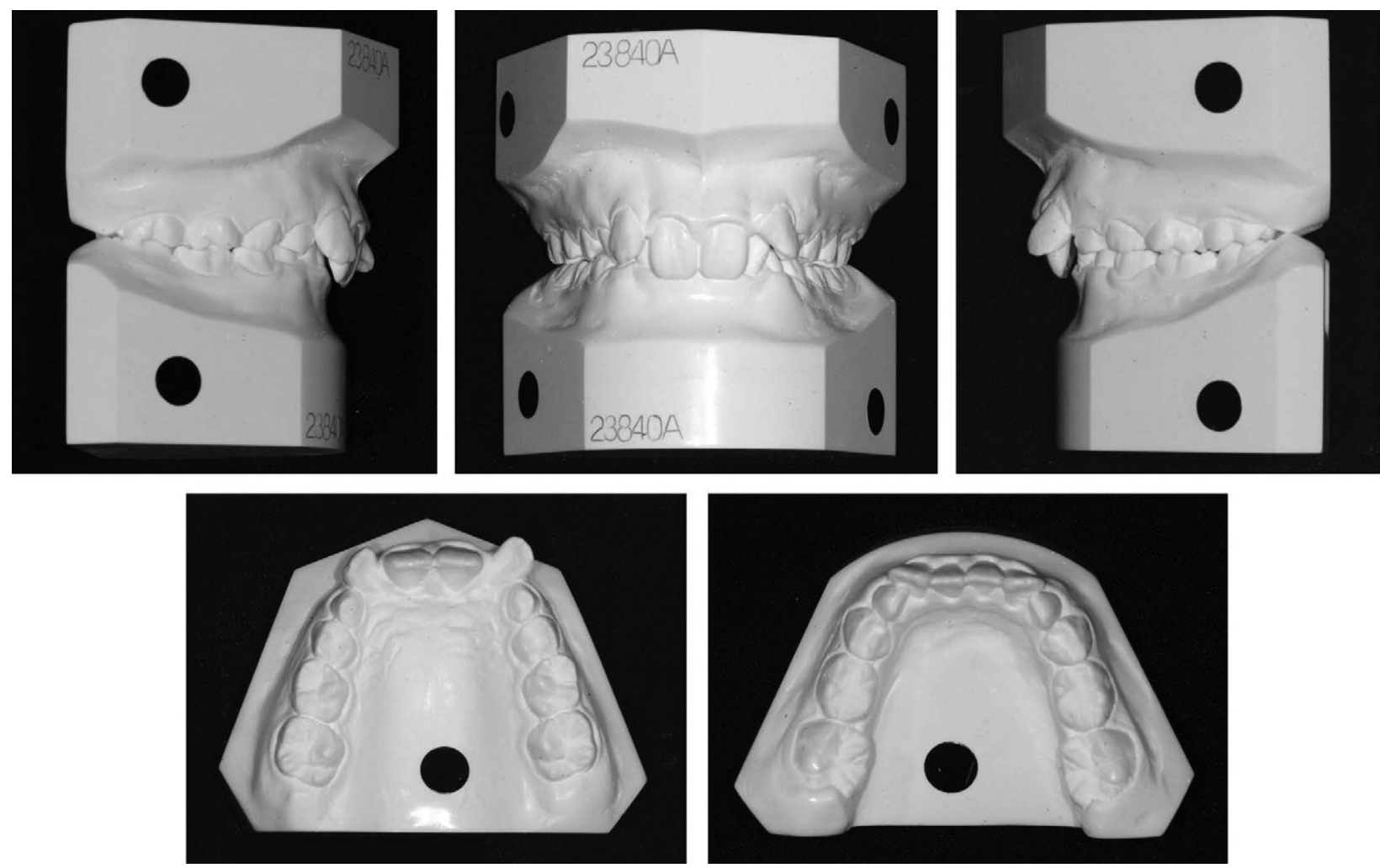

Fig 2. Pretreatment dental casts. 

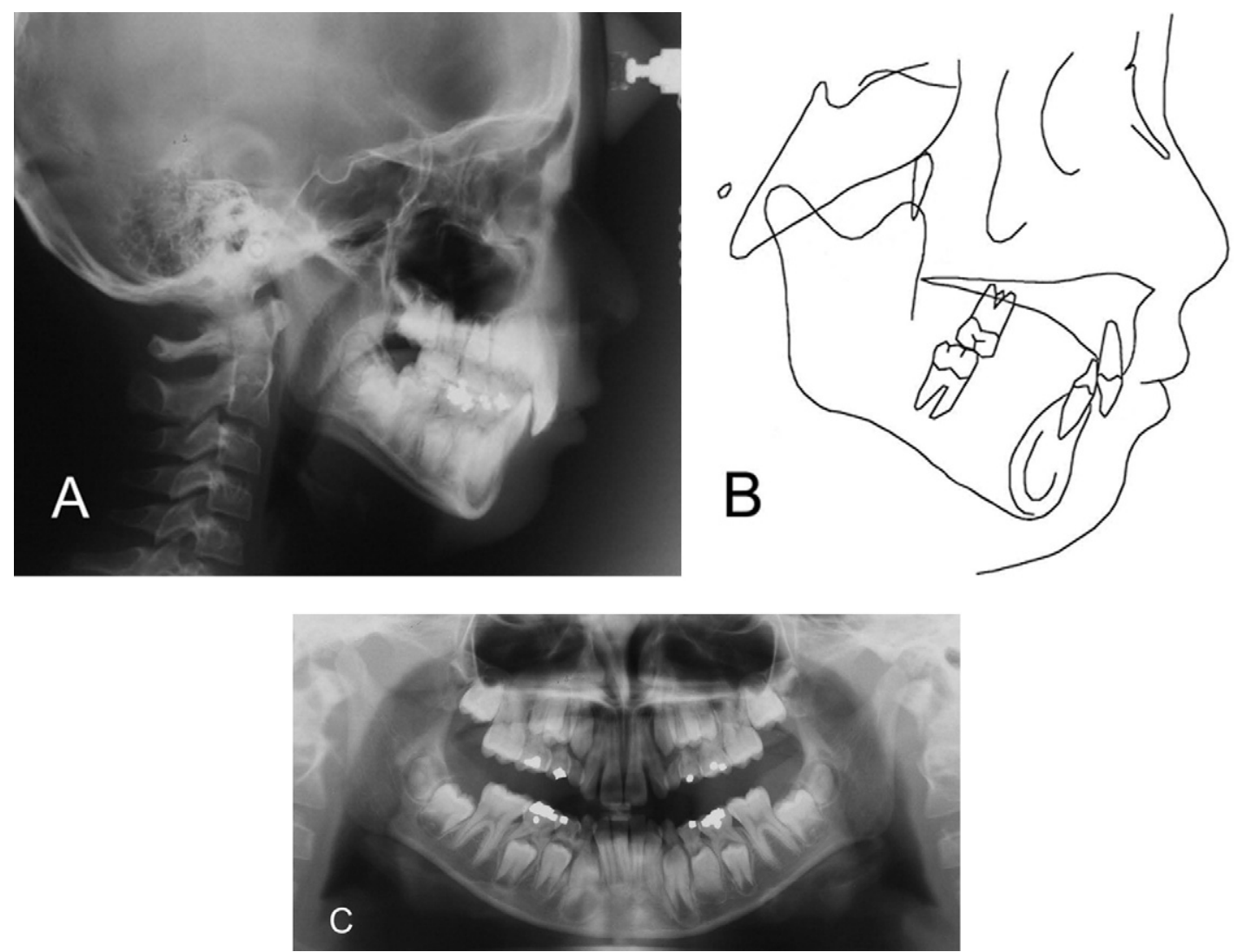

Fig 3. Pretreatment radiographs and cephalometric tracing.

was 8 to $9 \mathrm{~mm}$, resulting in overexposure of the maxillary incisors and gingiva on smiling. The upper lip was normal in length.

Because the patient did not have a significant medical history, the malocclusion was considered developmental, especially because of the retardation of mandibular growth.

\section{TREATMENT OBJECTIVES}

The treatment objectives were to create a more ideal overbite and overjet relationship, reduce the exposure of the maxillary incisors and gingiva, reduce the anteroposterior skeletal discrepancy to improve the facial profile, and obtain Class I canine and molar relationships. For the first stage, the goal of treatment was to intrude and procline the maxillary central incisors and obtain some overjet for mandibular forward growth. While decreasing the overbite, the mandibular plane would be maintained. In contrast, opening of the mandibular plane after extrusion of the maxillary molars would make the mandible rotate backward and worsen the Class II skeletal pattern. During the second stage, the goal was to reduce the skeletal discrepancy anteroposteriorly, which would be obtained by facilitating the growth potential of the mandible with a functional appliance and restricting the downward and forward growth of the maxilla with an orthopedic appliance. In the third stage, the goal was to maintain the improvement gained in the first and second stages, and to achieve a functional occlusion with fixed appliances.

\section{TREATMENT ALTERNATIVES}

Two alternatives for intruding and proclining the maxillary central incisors were presented to the patient: (1) a maxillary $2 \times 4$ appliance and high-pull headgear with a transpalatal arch, or (2) intrusion mechanics with a mini-implant and a segmented wire. The second plan was selected with the parents' consent. The miniimplant can provide absolute intrusion of the maxillary incisors without extrusion of the maxillary molars, which can open the mandibular plane clockwise.

To reduce the skeletal discrepancy anteroposteri- 

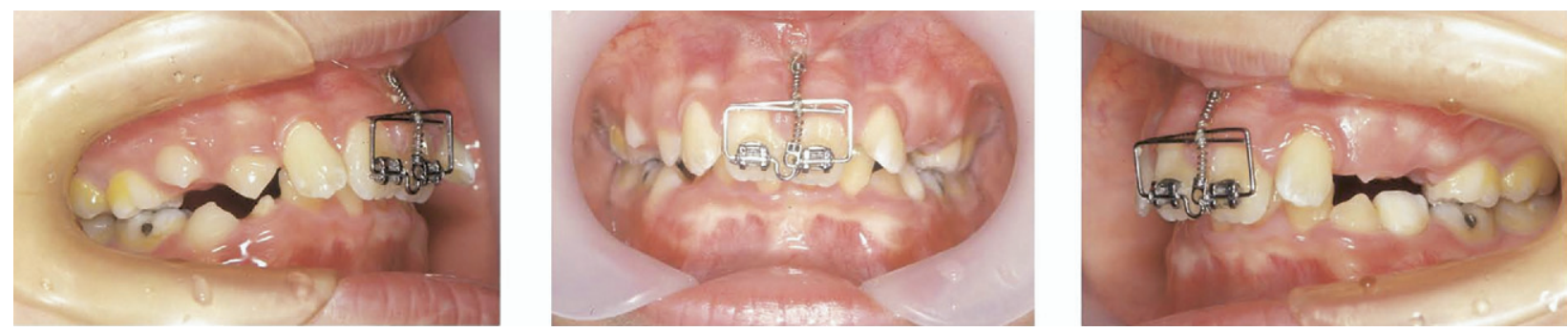

Fig 4. Progress intraoral photographs, 3 months after start of treatment.
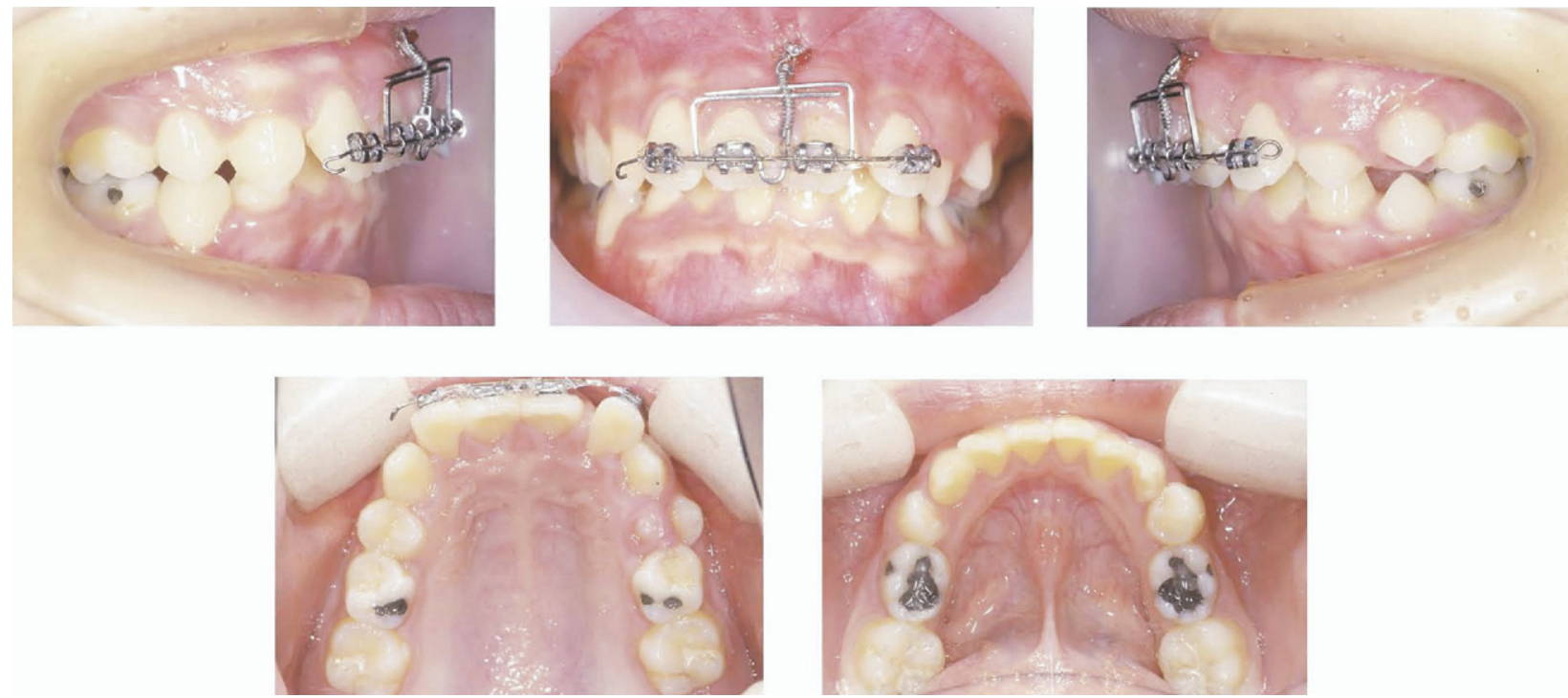

Fig 5. Progress intraoral photographs, 6 months after start of treatment.

orly by growth modification, a functional Class II appliance-Twin-block with high-pull headgear-was planned for the second stage of treatment.

For the third stage, 2 possible alternatives were explained to the parents: if the result of the second stage was adequate, edgewise fixed appliances would be used to achieve a functional occlusion; or if the result of the second stage was not good enough to obtain a functional occlusion with orthodontic treatment alone, the patient's growth would be observed until the end of growth, and orthodontic treatment would be combined with orthognathic surgery to finish the occlusion.

\section{TREATMENT PROGRESS}

Initially, 2 brackets (.022-in slot, MBT, 3MUnitek, Monrovia, Calif) were bonded to the central incisors. After leveling, a box-shaped segmental wire made of $.019 \times 025$-in stainless steel was ligated to the brackets (Fig 4). The upper horizontal portion of the wire was used to keep the nickel-titanium spring from impinging on the gingiva (Figs 4, 5, and 6, A).
A mini-implant $(1.6 \times 6.0 \mathrm{~mm}$, OSAS, Epoch Medical, Seoul, South Korea) was placed without drilling between the roots of the maxillary central incisors under the anterior nasal spine. A nickeltitanium closed-coil spring was ligated from the head of the screw to the wire.

The 2 central incisors moved labially and apically. Five months later, when the central incisors intruded to the level of the lateral incisors, brackets were bonded on the lateral incisors, and a .014-in stainless steel wire was ligated over the box wire. At this stage, the 4 maxillary incisors began to intrude, so at the next appointment, an .018-in stainless steel wire was placed (Fig 5), and a power chain was used to close the space. At this appointment, a cephalogram was taken, and the tracing was superimposed on the pretreatment tracing (Fig 6, $B-D$ ). The maxillary incisors were intruded and tipped labially without movement of the maxillary first molars, and, without direct force application, the mandibular incisors tipped labially and showed some alignment (Fig 5). Also, mandibular growth or 

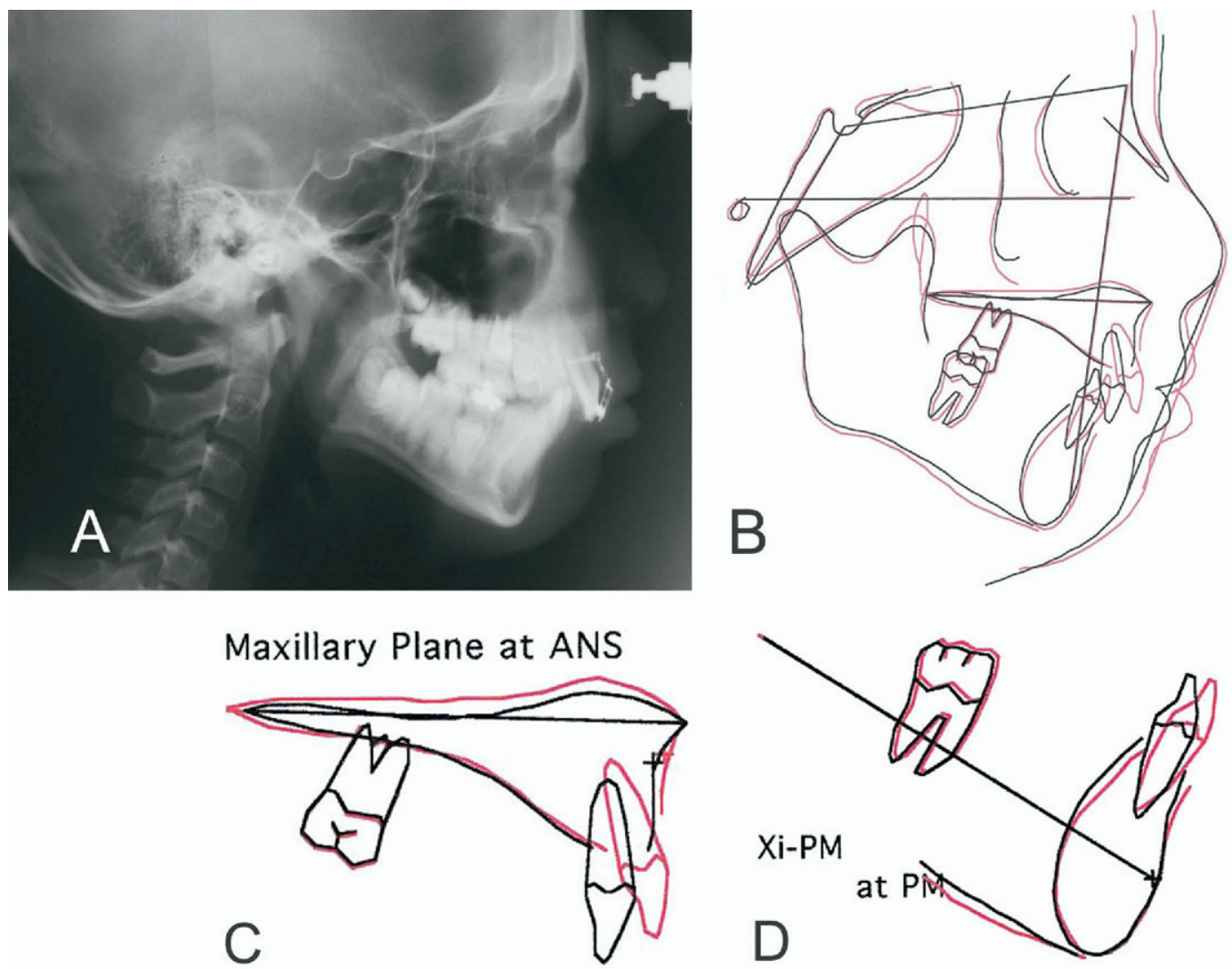

Fig 6. Six-month progress radiograph and superimposition of progress (red) and pretreatment tracings (black).

displacement was noted (Fig 6, $B$ ). The patient's gummy smile had disappeared.

The mini-implant was removed in a second operation. It was stable for 7 months. A $2 \times 4$ appliance was placed while awaiting eruption of the permanent teeth (Fig 7). With intrusion and proclination of the maxillary incisors with a mini-implant at the first stage, the original Class II Division 2 pattern had changed to a Class II Division 1 pattern. This change made it possible to use a functional Class II appliance, the Twin-block. ${ }^{4}$ The Twin-block was used with high-pull headgear, which the patient wore for 8 hours a day to restrict downward and forward growth of the maxilla. The mandibular arch was expanded a little with an expansion screw to resolve the anterior crowding. The Twin-block was used for 6 months.

After obtaining an improved anteroposterior relationship at the second stage, a maxillary inclined plane was used for 5 months. ${ }^{4}$ This anterior inclined plane maintained the corrected maxillomandibular relationship until the buccal segment occlusion was fully interdigitated with edgewise fixed appliances. Bonding was delayed until the second molars were fully erupted (Fig 8). Total active treatment of the third stage with the edgewise appliances was 14 months. After debonding, a modified activator was used as a retainer at night, and circumferential retainers were used during the day (Table I).

\section{TREATMENT RESULTS}

Total treatment time was 2 years 3 months. The original treatment objectives were achieved because of excellent patient cooperation. The mini-implant was well tolerated, without complications, and the patient did not complain of irritation. Facial harmony was good, and the gummy smile and deep overbite had disappeared (Fig 9). The posttreatment intraoral photos (Fig 9) and dental casts (Fig 10) show a Class I canine and molar relationship. Overbite and overjet were overcorrected. The final cephalogram and its superimposition with the pretreatment tracing show substantial growth of the mandible without opening the mandibular plane (Fig 11, Table II). The forward growth of the maxilla was well restrained. The final interincisal angle of $124^{\circ}$ was in the normal range (Table II). Because ANB angle was greater 

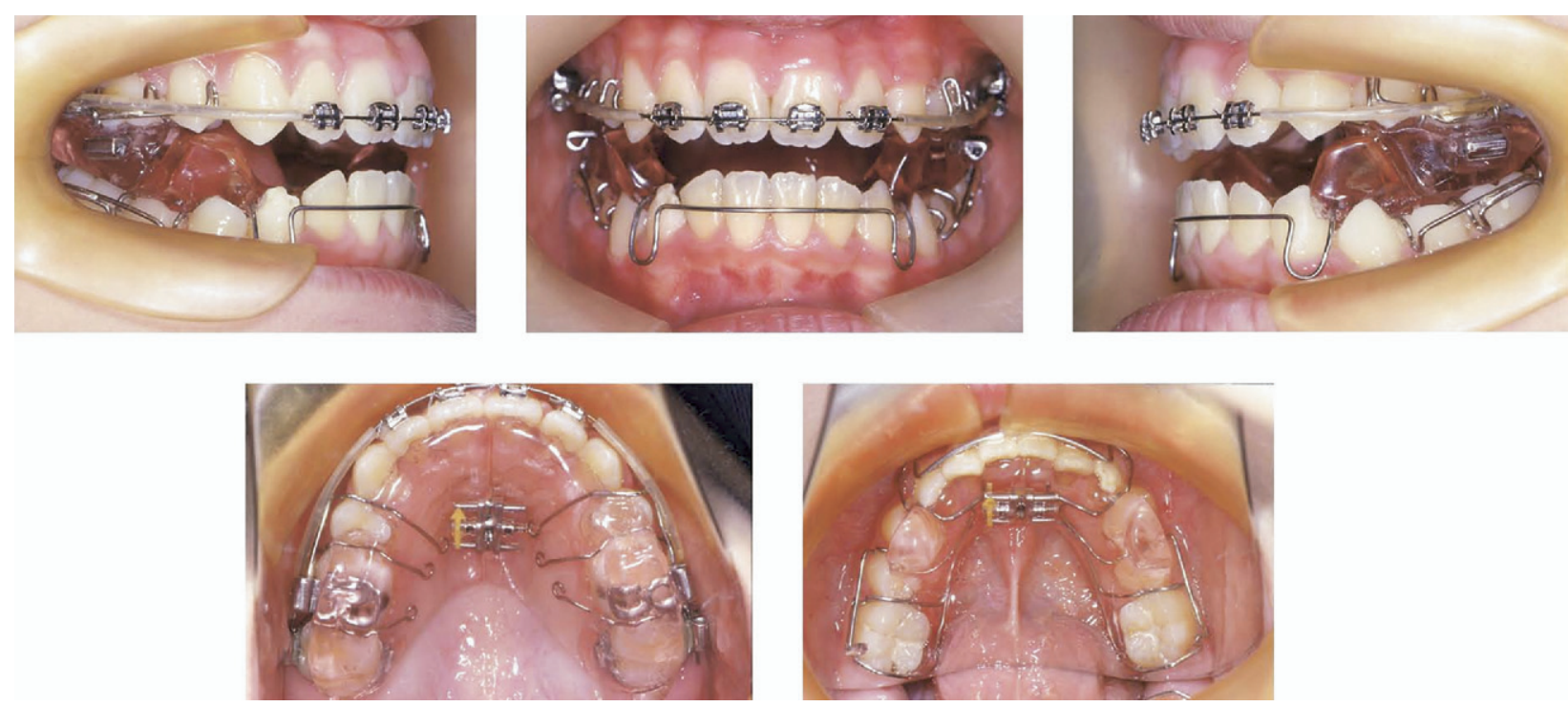

Fig 7. Progress intraoral photographs, 10 months after start of treatment.
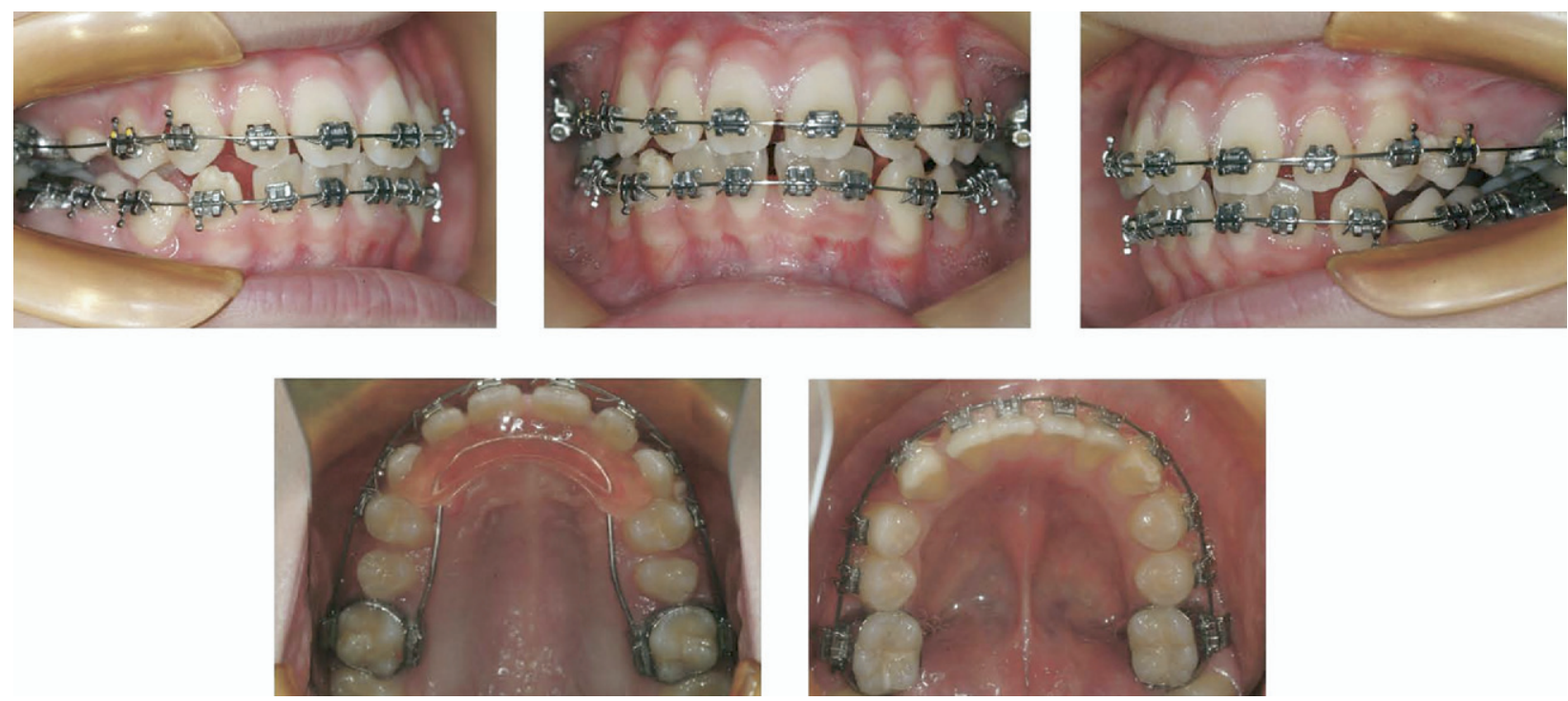

Fig 8. Intraoral photographs after 17 months of treatment.

Table I. Summary of treatment progress

\begin{tabular}{llll}
\hline Stage & \multicolumn{1}{c}{ Goal } & \multicolumn{1}{c}{ Appliances } & \multicolumn{1}{c}{ Duration } \\
\hline 1 (Figs 4 and 5) & Intrusion and proclination of maxillary incisors & Mini-implant & 7 months \\
& & Segmented wire & Nickel-titanium closed-coil spring \\
2 (Fig 7) & Growth modification & $2 \times 4$ maxillary arch & Twin-block \\
& & High-pull headgear & months \\
3 (Fig 8) & Detailing interdigitation & Maxillary inclined plane (5 months) & 14 months \\
& & Edgewise appliance &
\end{tabular}



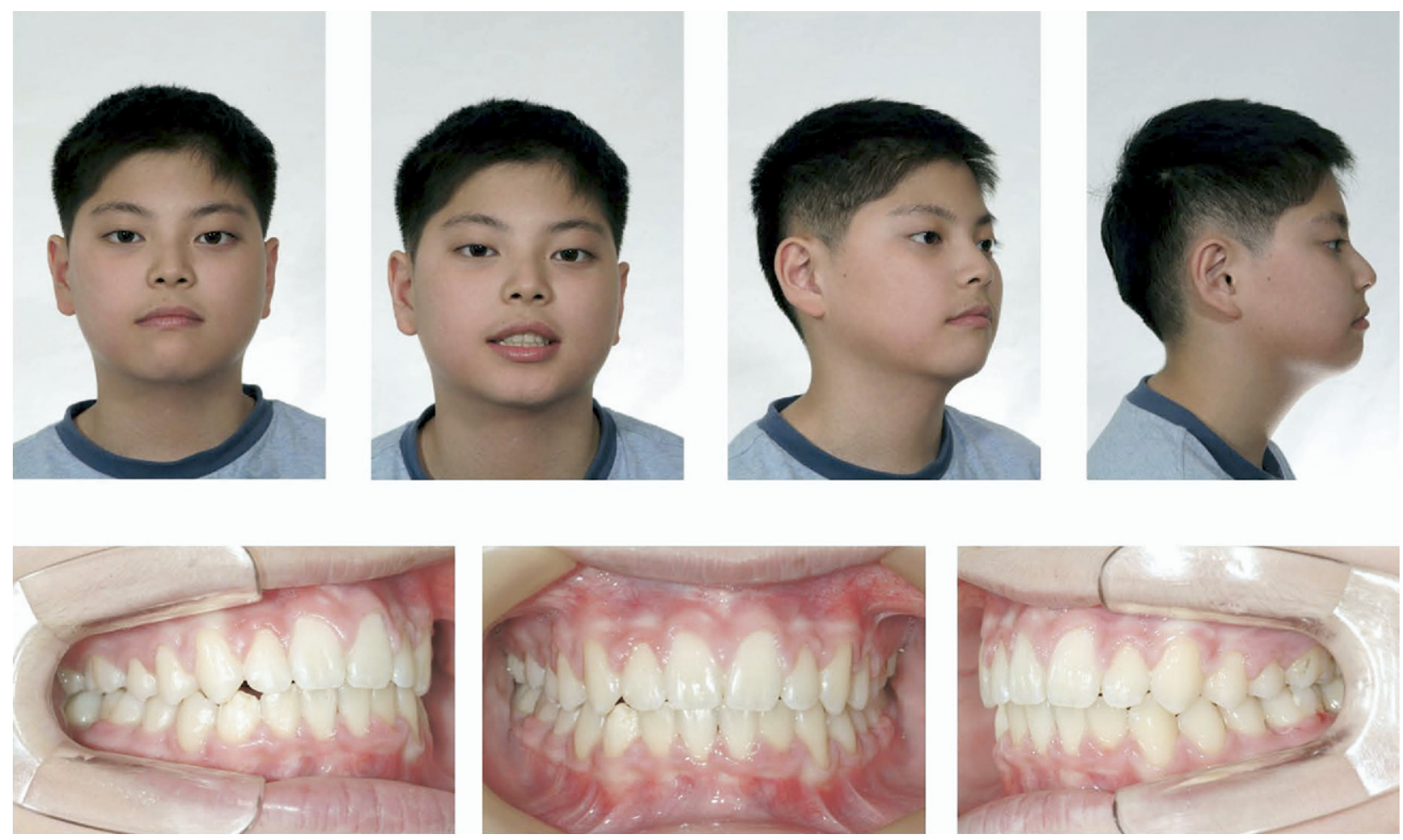

Fig 9. Posttreatment photographs at age 12 years 8 months.
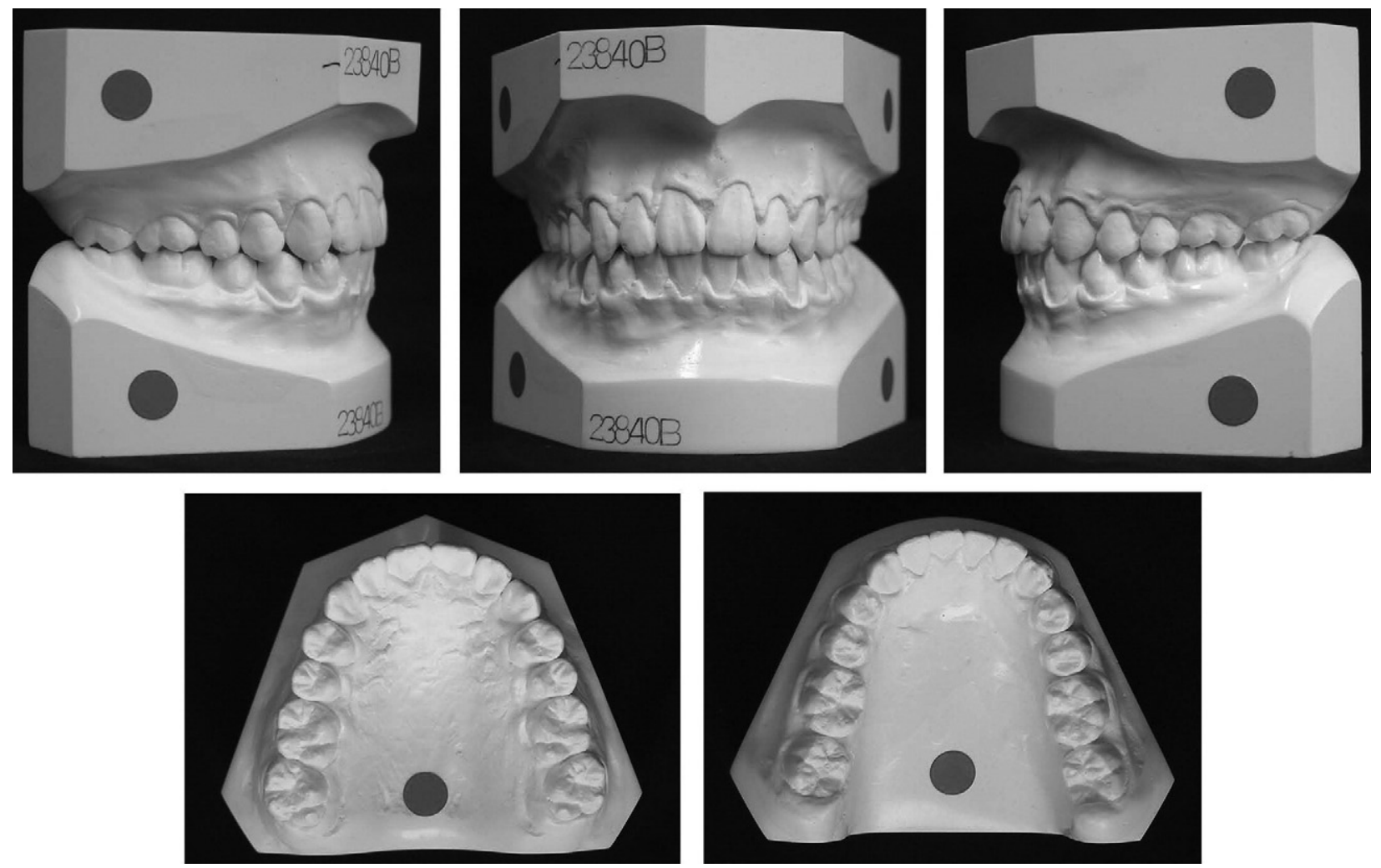

Fig 10. Posttreatment dental casts. 

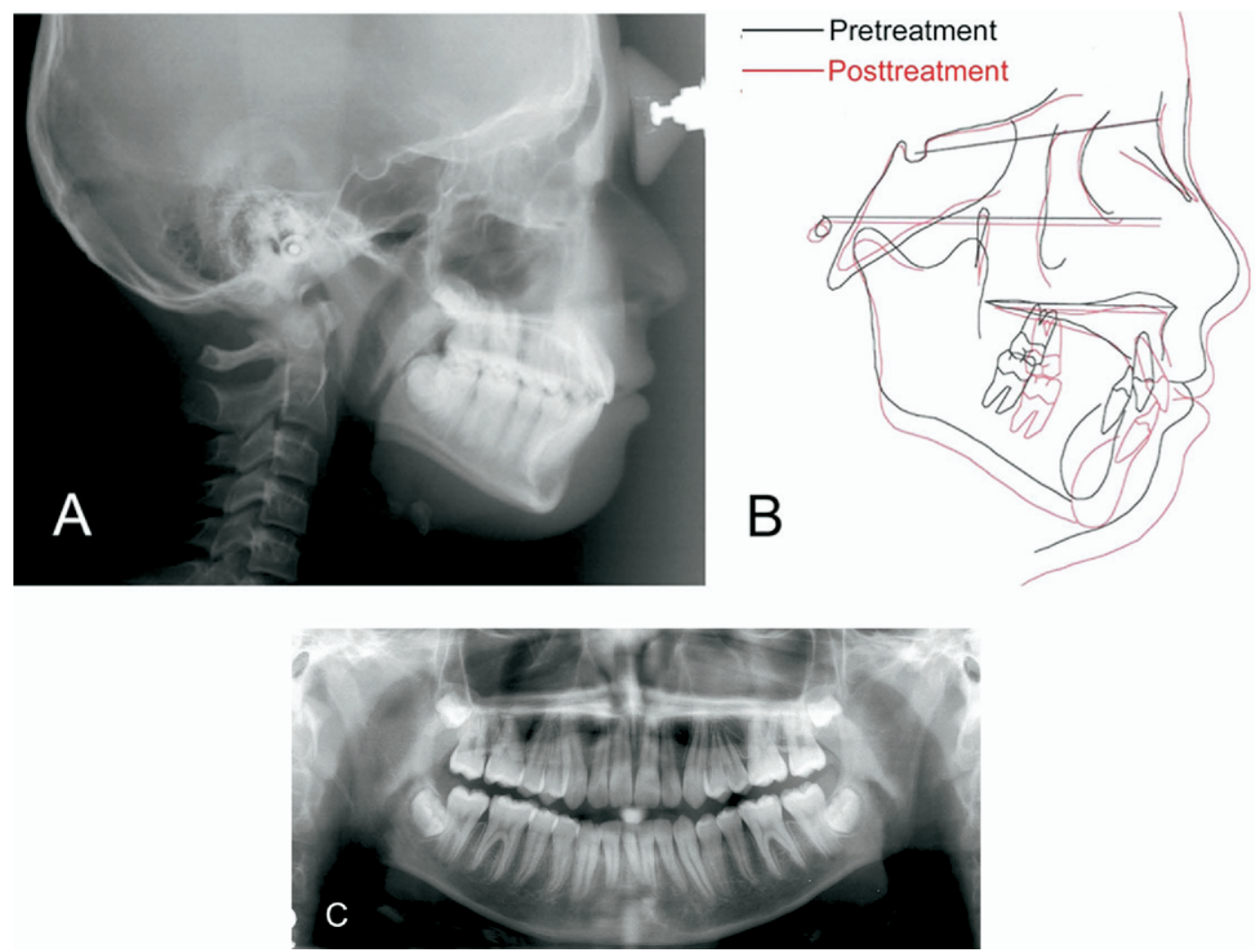

Fig 11. Posttreatment radiographs and superimposition of posttreatment (red) and pretreatment (black) tracing.

than the norm and the patient was still growing, observation until the end of growth is required. The orthopantomogram confirms acceptable root parallelism.

\section{DISCUSSION}

With this treatment, we attempted to intrude the maxillary incisors and reduce the gummy smile using only a mini-implant and a segmented wire. This intrusion system has been used by the author (T.-W.K.) efficiently in gummy-smile patients with severely overerupted and retroclined incisors, either Class II Division 2 or Class I.

Gummy smiles can be divided into several categories according to etiologic factors. ${ }^{5-8}$ Dentoalveolar gummy smile occurs because of overeruption of the maxillary incisors relative to the upper lip. The dentogingival type, related to abnormal dental eruption, gingival hyperplasia, or lack of gingival recession is evidenced by short crown height. 9 A gummy smile of skeletal origin occurs because of excessive vertical height of the maxilla; this requires orthognathic surgery. ${ }^{7,10} \mathrm{~A}$ short upper lip is also a frequent cause of a gummy smile. ${ }^{7}$ The muscular type is caused by hyperactivity of the
Table II. Cephalometric summary

\begin{tabular}{lrrrr}
\hline & Norm & \multicolumn{1}{c}{ T1 } & \multicolumn{1}{c}{$T 2$} & \multicolumn{1}{c}{ T3 } \\
\hline SNA angle $\left(^{\circ}\right)$ & 81.8 & 83.0 & 85.0 & 82.5 \\
SNB angle $\left(^{\circ}\right)$ & 80.2 & 74.0 & 75.0 & 76.0 \\
ANB angle $\left(^{\circ}\right)$ & 1.8 & 9.0 & 10.0 & 6.5 \\
FMA $\left(^{\circ}\right.$ ) & 26.8 & 28.5 & 26.0 & 27.5 \\
U1 to FH $\left(^{\circ}\right)$ & 116.5 & 86.0 & 104.0 & 109.5 \\
IMPA $\left(^{\circ}\right)$ & 90.2 & 79.0 & 96.0 & 100.5 \\
Interincisal angle $\left(^{\circ}\right)$ & 126.2 & 159.5 & 136.5 & 124.0 \\
Upper lip (mm) & 0.0 & 1.8 & 2.0 & -0.5 \\
Lower lip (mm) & 0.8 & 2.2 & 5.9 & 2.0 \\
\hline
\end{tabular}

T1, Pretreatment records (Fig 3, B).

$T 2$, After intrusion of maxillary incisors (Fig 6, B).

T3, Posttreatment records (Fig 11, B).

elevator muscles of the upper lip. ${ }^{11}$ Finally, a gummy smile might be caused by several of these factors.

This patient had a dentoalveolar gummy smile. Only the maxillary central incisors were extruded, and the other posterior teeth were in normal vertical positions. In this category, if the extruded incisors are intruded well as in this patient, the gummy smile and the deep overbite can be corrected efficiently. 

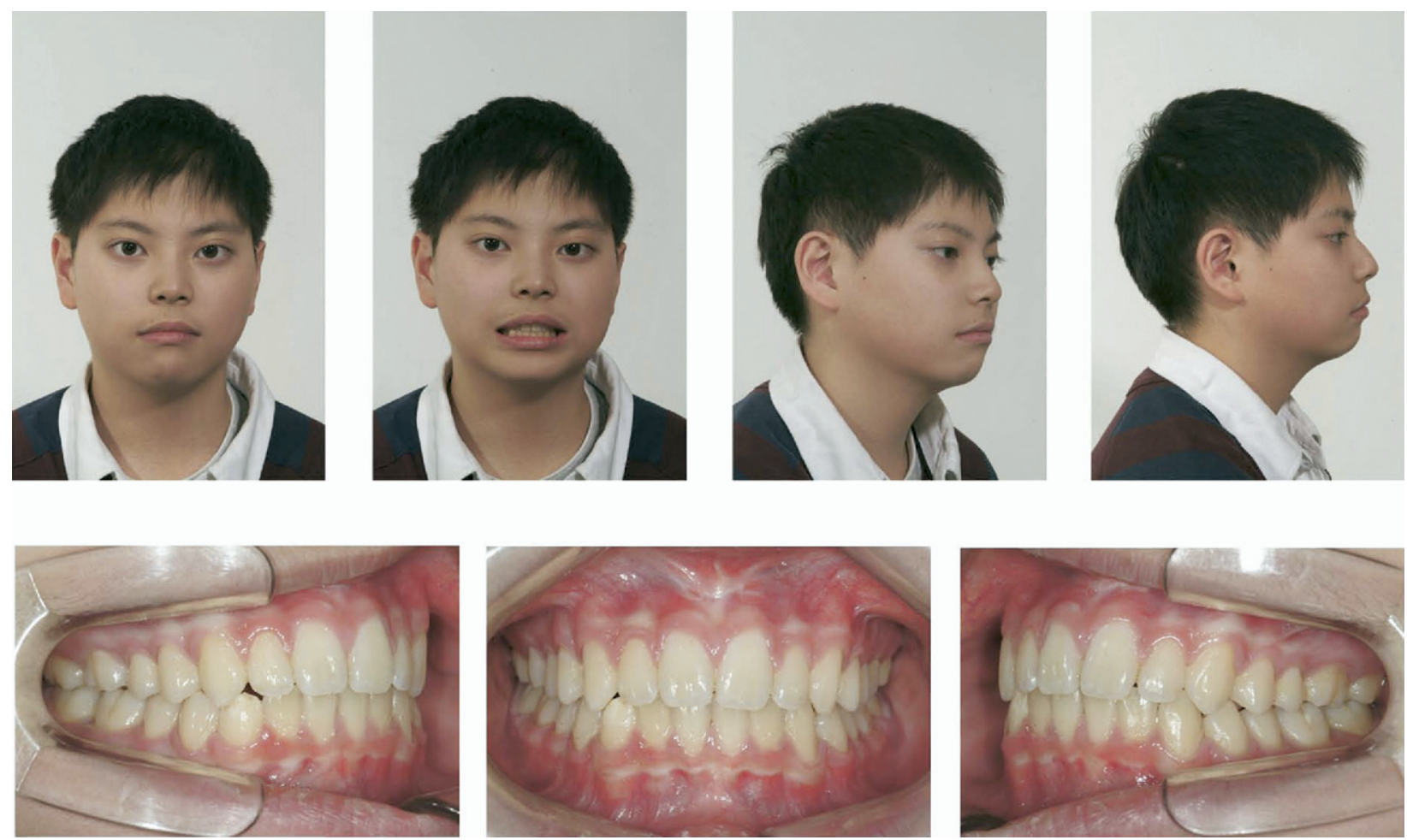

Fig 12. One-year postretention photographs.

This method was first introduced by Creekmore and Eklund $^{1}$ and recently reported by Ohnishi et al. ${ }^{3}$ Our patient was treated with a segmented wire ligated only to the maxillary incisors; this prevented extrusion of other teeth. The effects and indications of this system are similar to those of the 1-piece intrusion arch by Burstone ${ }^{8}$ or the utility archwire used by Ricketts et al. ${ }^{12}$ The mini-implant with a segmented wire has some advantages. First, it does not cause extrusion of the maxillary molars; this otherwise might open the mandibular plane, rotate the mandible clockwise, move menton downward and backward, and worsen a retrusive profile. Second, the patient's cooperation with wearing high-pull headgear is not required to obtain intrusion and labioversion of the incisors.

At the first stage, intrusion was initiated with segmental wires on the central incisors (Fig 4) and then extended to the lateral incisors as treatment progressed (Fig 5). A continuous archwire or a utility archwire might have produced an extrusive force on the lateral incisors. This simple intrusive system obtained intrusion and labioversion of the maxillary incisors in 6 months (Fig 6). When superimposing the maxillary incisor at the maxillary plane, the maxillary incisors had 4-mm intrusion and labioversion of $18^{\circ}$ (Fig 6, C, and Table II). When superimposing the mandibular incisor at protuberance menti point, the mandibular incisors showed labioversion (Fig 6, D). IMPA increased from $79^{\circ}$ to $96^{\circ}$ (Table II); this provided space for the mandibular anterior crowding to be resolved.

After intrusion and labioversion of the maxillary incisors with the mini-implant, the patient's dental characteristics changed from Class II Division 2 with deep overbite to a straightforward case for the use of the Twin-block; this satisfied the following criteria suggested by Clark ${ }^{4}$ : (1) Class II Division 1 with good arch form, (2) mandibular arch not crowded, (3) maxillary arch aligned or can be easily aligned, (4) overjet of 10 to $12 \mathrm{~mm}$ and deep overbite, (5) full unit distal occlusion in buccal segments, and (6) profile noticeably improved when the patient advances the mandible voluntarily to correct the overjet.

Although the patient's profile and anteroposterior relationship were improved, ANB angle was still a little greater than the norm, and the mandible was retrusive. Above all, at debonding, the patient was only 12 years 8 months old. For these reasons, a Class II activator with upper and lower labial bows was used at night. One year later, his occlusion showed a good Class I relationship (Fig 12). The patient's growth needs continuous observation to ensure long-term stability. 


\section{CONCLUSIONS}

A boy, aged 10.5 years, with a Class II molar relationship and a very deep overbite, complaining of gummy smile and anterior crowding, was treated nonextraction with a mini-implant and Twin-block and edgewise fixed appliances.

1. Severely extruded and retroclined maxillary incisors were intruded and proclined with a miniimplant and a segmented wire; this resolved the gummy smile and the deep overbite efficiently without extruding the maxillary molars or opening the mandible.

2. The mini-implant was stable for 7 months during treatment and was accepted well by the patient. Force was applied immediately after its placement.

3. The mandibular incisors were proclined without direct orthodontic force during intrusion of the maxillary incisors; this helped the nonextraction treatment of mandibular crowding.

4. The Twin-block with high-pull headgear promoted mandibular growth while restraining maxillary growth and changed the canine and molar relationship from Class II to Class I.

5. The patient's overbite and overjet were overtreated, and, 1 year postretention, the patient maintained a good overbite and overjet.

\section{REFERENCES}

1. Creekmore TM, Eklund MK. The possibility of skeletal anchorage. J Clin Orthod 1983;17:266-9.

2. Kanomi R. Mini-implant for orthodontic anchorage. J Clin Orthod 1997;31:763-7.

3. Ohnishi H, Yagi T, Yasuda Y, Takada K. A mini-implant for orthodontic anchorage in a deep overbite case. Angle Orthod 2005;75:444-52.

4. Clark WJ. Twin-block functional therapy: applications in dentofacial orthopaedics. London: Mosby-Wolfe; 1995. p. 23.

5. Monaco A, Streni O, Marci MC, Marzo G, Gatto R, Giannoni M. Gummy smile: clinical parameters useful for diagnosis and therapeutical approach. J Clin Pediatr Dent 2004;29:19-25.

6. Robbins J. Differential diagnosis and treatment of excess gingival display. Pract Periodontics Aesthet Dent 1999;11:265-72.

7. Proffit WR, White RP Jr, Sarver DM. Contemporary treatment of dentofacial deformity. St Louis: Mosby; 2003. p. 111, 500-6.

8. Burstone CJ. Deep overbite correction by intrusion. Am J Orthod 1977;72:1-22.

9. Redlich M, Mazor Z, Brezniak N. Severe high Angle Class II Division 1 malocclusion with vertical maxillary excess and gummy smile: a case report. Am J Orthod Dentofacial Orthop 1999;116:317-20.

10. Ataoglu H, Uckan S, Karaman AI, Uyar Y. Bimaxillary orthognathic surgery in a patient with long face: a case report. Int J Adult Orthod Orthognath Surg 1999;14:304-9.

11. Miskinyar SA. A new method for correcting a gummy smile. Plast Reconstr Surg 1983;72:397-400.

12. Ricketts RM, Bench RW, Gugino CF, Hilgers JJ, Schulhof RJ. Bioprogressive therapy. Denver: Rocky Mountain Orthodontics; 1979. p. 111-26. 